\title{
Development of dispersive solid-phase microextraction coupled with high-pressure liquid chromatography for the preconcentration and determination of the selected neonicotinoid insecticides
}

Ngwako Joseas Waleng ${ }^{1,2}$, Shirley Kholofelo Selahle ${ }^{1,2}$, Anele Mpupa ${ }^{1,2}$ and Philiswa Nosizo Nomngongo $0^{1,2,3^{*}}$ (D)

\begin{abstract}
Neonicotinoid insecticides have raised a lot of societal concerns due to their environmental ubiquity and unique mode of action. Therefore, it is of great research interest to monitor their occurrence in the environmental waters. However, these compounds exist at low concentrations that is below instrument detection limits. This study reports the applicability of magnetic poly ( 3 aminobenzoic acid)-based activated carbon ( $\left.\mathrm{Fe}_{3} \mathrm{O}_{4} @ P A B A / A C\right)$ composite as an adsorbent in dispersive magnetic solid-phase microextraction ( $d$-MSPME) of neonicotinoid insecticides from wastewater and river water samples. The as-synthesized adsorbent was characterized and confirmed by Fourier transform infrared spectroscopy, scanning electron microscopy, transmission electron microscopy, Brunauer-Emmett-Teller and X-ray diffraction spectroscopy. The analytes of interest were detected and quantified by high-performance liquid chromatography coupled with diode array detector (HPLC-DAD). The parameters affecting the extraction and preconcentration processes, such as $\mathrm{pH}$, extraction time, mass of adsorbent, desorption time and eluent volume, were optimized using fractional factorial design and central composite design. Under optimum conditions, the limits of detection and quantification were in the ranges of $0.41-0.82 \mu \mathrm{g} \mathrm{L}^{-1}$ and $1.4-2.7 \mu \mathrm{g} \mathrm{L}{ }^{-1}$, respectively. The linearity ranged from $1.4-700 \mathrm{\mu g} \mathrm{L}^{-1}$ with correlation of determination $\left(R^{2}\right)$ values varied between 0.9933 and 0.9987 . The intra-day and inter-day precisions were $0.35-0.75 \%$ and $1.7-5.5 \%$, respectively. The spike recovery experiments were conducted to evaluate the accuracy of the $d$-MSPME analytical method in real samples, and the percentage recoveries ranged from 86.7 to $99.2 \%$. Therefore, this method shows great potential applicability in preconcentrating the pollutants from the environment.
\end{abstract}

Keywords: Neonicotinoid insecticides, $\mathrm{Fe}_{3} \mathrm{O}_{4} @ P A B A / A C$ composite, Central composite design, Fractional factorial design, Magnetic solid-phase microextraction

\footnotetext{
*Correspondence: pnnomngongo@uj.ac.za

1 Department of Chemical Sciences, University of Johannesburg,

Doornfontein Campus, P.O. Box 17011, Johannesburg 2028, South Africa

Full list of author information is available at the end of the article
}

\begin{abstract}
Introduction
Recently, access to clean water has become a global concern. The remarkable increase in human population has triggered high industrialization and agricultural production to meet mankind sustainability (Munonde 2017). These activities lead to increased use of various chemical substances that are then released into the environment. Among these chemical substances, neonicotinoid
\end{abstract}


insecticides (also known as neonics) are the mostly distributed into the environment via agricultural practices (Vichapong et al. 2015). Neonicotinoid insecticides are a relatively new class of insecticides derived from nicotine, and they were introduced in the 1990s for insects control (Yáñez et al. 2014; Farajzadeh et al. 2016). They act agonistically at the nicotinic acetylcholine receptors (nAChRs) on the post-synaptic layer. These receptors contribute greatly to signal transmission in the central nervous system (CNS) (Vichapong et al. 2013; Jovanov et al. 2013; Zhao et al. 2020; Guo et al. 2020; Yamamoto and Casida 1999). Neonicotinoids bind tightly to the nAChRs of insects than to any other organism including mammals, and the latter can cause paralysis or even death. However, these compounds are considered less toxic to mammals (Farajzadeh et al. 2016; Zou et al. 2019; Mahai et al. 2019).

Several nations have drafted the allowable residue limits of these compounds in various environmental matrices (Zhao et al. 2020; Pietrzak et al. 2020). Moreover, European Union (EU) legislation has established the strict regulations for the maximum consumable residue limits of the neonicotinoids in various agricultural products and water. The ubiquity of these compounds in the environmental waters is of great global concern, and according to the EU legislation, the total maximum permissible levels for neonicotinoids and their metabolites should be $1.05 \mu \mathrm{g} \mathrm{L}^{-1}$ (Anzecc 2000; Yi et al. 2019). Each neonicotinoid insecticide can produce various metabolites depending on the environmental conditions. It is worth noting that the current work focuses on the actual neonicotinoids rather than the metabolites. Neonicotinoids can in turn become toxic to humans and other animals if they are continuously consumed in amounts exceeding maximum residue limits (MRLs). Therefore, proper monitoring and removal of these compounds are necessary to promote the safety of terrestrial and aquatic organisms (Sánchez-Bayo and Hyne 2014).

High-performance liquid chromatography (HPLC) coupled with different suitable detectors including fluorescence (Treder et al. 2020), diode array detector (Arase et al. 2016; Zhou et al. 2006), and tandem mass spectrometry (Ike et al. 2018; Kachangoon et al. 2020) have attracted a lot of attention for the analysis of organic pollutants including neonicotinoids owing to its superior sensitivity and reliability (Song et al. 2018). However, the direct analysis of the neonicotinoids by HPLC is difficult due to their low concentrations in complex environmental matrices (Arnnok et al. 2017; Azzouz et al. 2018). Therefore, a sample pre-treatment technique is needed prior to their quantitative analysis. Recently, numerous sample pre-treatment techniques have been reported (Guo et al. 2020). To date, researchers are still using traditional sample preparation methods such as solid-phase extraction (SPE) (Furman et al. 2010; Mpupa et al. 2019; Georgakopoulos et al. 2011) and liquid-phase extraction (LLE) (Jovanov et al. 2013; Peyton 1993; Rodríguez et al. 2016). However, these techniques are tedious, laborious, expensive and environmentally unfriendly. In addition, LLE requires large volumes of toxic organic solvents (Zou et al. 2019). Therefore, new methods based on the miniaturization of the traditional procedures, improvement of selectivity to minimize matrix effects and reduction in sample pre-treatment steps and time are necessary (Ike et al. 2018; Kachangoon et al. 2020). To mitigate the aforementioned setbacks, microextraction techniques that have been developed include solid-phase microextraction (SPME) (Zhao et al. 2015; Jiang et al. 2015), liquid-phase microextraction (LPME), dispersive solid-phase microextraction ( $d$-SPME), dispersive liquidphase microextraction ( $d$-LPME) (Javadi et al. 2020) and cloud point extraction (CPE) (Ghouas et al. 2016), among others. These techniques can selectively preconcentrate the analytes of interest and subsequently clean-up the sample matrix with greater efficiency. The current work applies $d$-SPME using magnetic nanoparticles referred to as magnetic dispersive solid-phase microextraction ( $d$-MSPME) which has been reported in the literature (Mpupa et al. 2019; Georgakopoulos et al. 2011; Spietelun et al. 2013; Giakisikli and Anthemidis 2013). This method offers great advantages such as the use of small organic solvents volumes, short extraction times, simpler operation and facile sorbent regeneration (Mehdinia and AzizZanjani 2013).

Various nanostructured magnetic-based materials have been utilized in sample preparation methods owing to their unique physical and chemical properties. The super-paramagnetism properties of these materials enable them to be easily separated by the external (Biswas et al. 2020; Zhang et al. 2019). Additionally, the magnetic materials containing the pollutants can be magnetically recovered from the sample matrix by applying external magnet (Giakisikli and Anthemidis 2013; Vu et al. 2017). Recently, carbon-based materials have been extensively explored in sample preparation methods owing to their high adsorption capacities and extraction recoveries for organic pollutants (Chisvert et al. 2019; Zhang et al. 2013; Ebrahimi et al. 2019). Among these materials, activated carbon has shown interesting features such as high surface area, abundant surface functionalities, meso- and micro-porosity, abundant precursors and affinity to organic pollutants (Mui et al. 2010; Mogolodi Dimpe and Nomngongo 2019; Albishri et al. 2017). However, this material has poor selectivity towards a wide range of organic pollutants. Additionally, activated carbon lacks dispersibility. 
In this work, poly (3 aminobenzoic acid) (PABA) was introduced to improve the properties of activated carbon. Poly (3 aminobenzoic acid) is a hydrophilic, conductive and chemically stable polymer, and it has high dispersibility characteristics (Ramohlola et al. 2017a). The incorporation of PABA into AC can strengthen various factors by tuning the morphologies and structural properties of the parent material (Ramohlola et al. 2017b). To the best of our knowledge, this is the first study reporting the application of magnetic PABA-based AC for the preconcentration of neonicotinoids in real water samples. Four neonicotinoids that are mostly found in environmental wastewater, acetamiprid (ACT), imidacloprid (IMD), thiacloprid (TCL) and clothianidin (CLD), were selected as the analytes. The preconcentration technique was revealed to be satisfactory for the simultaneous determination of these analytes.

\section{Experimental}

\section{Materials, reagents, and standards}

Acetamiprid (ACT), imidacloprid (IMD), thiacloprid (TCL) and clothianidin (CLD), 3-aminobenzoic acid, ammonium persulfate (APS), iron chloride tetrahydrate, iron chloride hexahydrate, acetonitrile (ACS reagent and HPLC grade), hydrochloric acid (37\%), sodium hydroxide, ammonium solution (25\%) and ethanol were purchased from Sigma-Aldrich (St. Louis, MO, USA). Tyre-based activated carbon was obtained by thermal treatment and subsequent $\mathrm{H}_{2} \mathrm{O}_{2}$ treatment for activation (Dimpe et al. 2018). A stock solution (100 mg/L) containing a mixture of ACT, IMD, TCL and CLD was prepared by accurately weighing each analyte, dissolving them in 100-mL acetonitrile, and the resulting solution was kept at $4{ }^{\circ} \mathrm{C}$. Working solutions were prepared daily by diluting appropriate volumes of the original stock solution with ultrapure water produced by Direct- $Q^{\circledR}$ 3UV-R purifier system, (Millipore, Merk, Germany), and ultrapure water was used throughout the experiments.

\section{Instrumentation}

Chromatographic analysis was carried out on a HPLC Agilent 1200 Infinity series, equipped with a diode array detector (Agilent Technologies, Waldbronm, Germany). The chromatograms were recorded at $268 \mathrm{~nm}$, $246 \mathrm{~nm}, 272 \mathrm{~nm}$, and $242 \mathrm{~nm}$ for CLD, ACT, IMD and TCL, respectively. An Agilent Zorbax Eclipse Plus C18 column $(3.5 \mu \mathrm{m} \times 150 \mathrm{~mm} \times 4.6 \mathrm{~mm})$ (Agilent, Newport, CA, USA) was operated at a column temperature of $25{ }^{\circ} \mathrm{C}$. The mobile phase composition contained a mixture of $70 \%$ water (mobile phase $\mathrm{A}$ ) and $30 \%$ acetonitrile (mobile phase B), using an isocratic elution system. A flow rate of $1.0 \mathrm{~mL} / \mathrm{min}$ was used throughout the analysis. The characterization of the synthesized materials was accomplished by the following analytical techniques: Infrared spectra were obtained using PerkinElmer spectrum 100 Fourier transform infrared spectrometer (Waltham, MA, USA) using a $\mathrm{KBr}$ disc technique. Surface area was obtained using Brunauer-Emmet-Teller surface area (SBET) by nitrogen adsorption-desorption mechanism in a Micrometric ASAP 2020, and all the gases used for analytical purposes were instrument grade. Sample pH was measured using OHAUS starter $2100 \mathrm{pH}$ meter (Pine Brook, NJ, USA). Crystallinity, particle sizes and amorphous nature of the materials were discovered by Powdered X-ray diffraction (X'Pert Phillips) with $\mathrm{CuK} \alpha$ radiation $(0.1540 \mathrm{~nm})$ polychromator beam in the $2 \theta$ scan range $20-800$ was carried to elucidate the crystallinity of the material. A step time and step size of 87.63 and $0.0170(2 \theta)$ was used at $40 \mathrm{kV}$ and $40 \mathrm{~mA}$ instrument power settings. External morphological features were explored by scanning electron microscope (SEM, TESCAN VEGA 3 XMU, LMH instrument (Czech Republic)) coupled to energy dispersive X-ray spectroscopy (EDS) for elemental composition at an accelerating voltage of $20 \mathrm{kV}$. Internal morphologies and particles sizes were obtained by transmission electron microscopy (TEM, JEM-200X, JEOL, Japan).

\section{Sample collection and preparation}

Water samples were collected from Apies river and Daspoort wastewater treatment plant (WWTP) at Pretoria, South Africa. Daspoort is known as the wastewater plant that treat the industrial wastewater $(5 \%$ of treated material) and domestic wastewater ( $95 \%$ of treated material). This plant uses activated sludge technology to treat wastewater. The effluent, influent and secondary wastewater were sampled and kept in glass sample bottles at $4{ }^{\circ} \mathrm{C}$. Prior to analysis, $0.45 \mu \mathrm{m}$ syringe filters were used to filter the samples.

\section{Preparation of poly ( 3 aminobenzoic acid) (PABA) and poly (3-amino benzoic acid)/activated carbon (PABA/AC) composite}

The synthesis of poly (3 amino benzoic acid) polymer was in accordance with the previously reported procedure (Ramohlola et al. 2017a). The preparation of poly (3 amino benzoic acid (PABA)-based activated carbon (PABA/AC) was by in situ chemical oxidative polymerization of $m$-aminobenzoic acid (3ABA) monomer along with an accurate amount of activated carbon. In short, approximately, $1 \mathrm{~g}$ of 3ABA monomer and $0.3 \mathrm{~g}$ of $\mathrm{AC}$ were introduced into $\mathrm{H}_{2} \mathrm{O} / \mathrm{HCl}(100 \mathrm{~mL} / 10 \mathrm{~mL})$ solution in a $250-\mathrm{mL}$ round bottom flask, and then the mixture was stirred for about $30 \mathrm{~min}$ at $50{ }^{\circ} \mathrm{C}$. Subsequently, $1.88 \mathrm{~g}$ of $\mathrm{FeCl}_{3}$ and $2.40 \mathrm{~g}$ of ammonium persulfate $\left(\mathrm{NH}_{4}\right)_{2} \mathrm{~S}_{2} \mathrm{O}_{8}$ were added to the solution, and 
the mixture was continuously stirred for $3 \mathrm{~h}$ at the same temperature. The mixture was then incubated in an oven overnight at $50{ }^{\circ} \mathrm{C}$ to evaporate the solvents, and the resulting content was then filtered and dried at $50^{\circ} \mathrm{C}$.

\section{Preparation of magnetic PABA/AC $\left(\mathrm{Fe}_{3} \mathrm{O}_{4} @ \mathrm{PABA} / \mathrm{AC}\right)$}

The synthesis of iron oxide nanoparticles followed the method reported previously with some modifications (Shabanian et al. 2015). The magnetic PABA/AC was obtained by following the procedure suggested by Wang et al. (2012). Briefly, an approximate amount of $\mathrm{FeCl}_{3} \cdot 6 \mathrm{H}_{2} \mathrm{O}(3.03 \mathrm{~g})$ and $\mathrm{FeCl}_{2} \cdot 4 \mathrm{H}_{2} \mathrm{O}(1.13 \mathrm{~g})$ were dissolved in $150 \mathrm{~mL}$ of deionized in a round bottom flask. The suspension was stirred for $30 \mathrm{~min}$ and the sodium dodecyl sulphate (SDS) was subsequently added, and the mixture was sonicated for $30 \mathrm{~min}$ to promote dispersion. The PABA/AC was then introduced into the solution mixture followed by heating up to $60{ }^{\circ} \mathrm{C}$ under $\mathrm{N}_{2}$ purging at a constant stirring. Ammonium solution $\left(\mathrm{NH}_{3} \mathrm{OH}\right.$, $25 \%$ ) was then used to adjust the $\mathrm{pH}$ of the solution to 10 followed by heating for about 30 min under vigorous stirring. The blackish brown precipitate was then collected by external magnet and washed several times with ethanol and distilled water, and the product was dried overnight at $60^{\circ} \mathrm{C}$.

\section{Dispersive magnetic solid-phase microextraction procedure (d-MSPME)}

The model sample solution of neonicotinoid insecticides $\left(10 \mu \mathrm{g} \mathrm{L}^{-1}\right)$ was prepared by diluting appropriate volume of the original standard solution of $1000 \mu \mathrm{g} \mathrm{L}^{-1}$. An amount of about 10-40 mg of $\mathrm{Fe}_{3} \mathrm{O}_{4} @ \mathrm{PABA} / \mathrm{AC}$ composite was then introduced into the sample bottle containing $5 \mathrm{~mL}$ of the model solution. The extraction of neonicotinoid insecticides into the solid-phase material was achieved by ultrasonication for 5-15 min followed by the application of an external magnet to separate the supernatant from the magnetic adsorbent containing analytes. The desorption of analytes from the adsorbent was carried by the addition of $100-1200 \mu \mathrm{L}$ of acetonitrile, and the mixture was sonicated for 5-20 min to elute the analytes from the adsorbent. The adsorbent and eluent were separated using an external magnet and the eluent was filtered using $0.22 \mu \mathrm{m}$ PVDF syringe filters and injected into the HPLC-DAD analysis. The most influential factors were optimized using fractional factorial design (FFD) and central composite design (CCD). The levels of each factor are shown in Table 1.

\section{Reusability procedure}

The reusability and regeneration of $\mathrm{Fe}_{3} \mathrm{O}_{4} @ \mathrm{PABA} /$ $\mathrm{AC}$ nanocomposite were studied by performing several adsorption-desorption cycles. The extraction and
Table 1 Parameters and levels applied in CCD for $d$-MSPME optimization

\begin{tabular}{lrlr}
\hline Factors & Low level (-1) & $\begin{array}{l}\text { Central } \\
\text { point } \\
\text { (0) }\end{array}$ & High level $(+\mathbf{1})$ \\
\hline Mass of adsorbent $(\mathrm{mg})$ & 10 & 25 & 41 \\
Extraction time $(\mathrm{min})$ & 5 & 10 & 15 \\
Desorption time $(\mathrm{min})$ & 5 & 12.5 & 20 \\
Eluent volume $(\mu \mathrm{L})$ & 100 & 550 & 1000 \\
$\mathrm{pH}$ & 4 & 6.5 & 9 \\
\hline
\end{tabular}

preconcentration experiments were conducted under optimum conditions, that is, $41 \mathrm{mg}, 1200 \mu \mathrm{L}, 10 \mathrm{~min}$, 5 min and 6.5 for MA, EV, ET, DT, and $\mathrm{pH}$, respectively. In each desorption process, the analyte-loaded adsorbent was mixed with $1200 \mu \mathrm{L}$ of acetonitrile and sonicated for $5 \mathrm{~min}$. The supernatant and adsorbent were separated using external magnet, and the supernatant was filtered through $0.22 \mu \mathrm{m}$ PVDF syringe filters. The analytes in the resultant filtrate were analysed using HPLC-DAD. The spent adsorbent was washed twice with deionized water followed by ethanol and dried in vacuum oven at $60{ }^{\circ} \mathrm{C}$ for $2 \mathrm{~h}$. The regenerated adsorbent was utilized for another adsorption-desorption cycle. The process was repeated several times until the adsorbent lost its adsorption capacity.

\section{Application to real samples}

The developed method was applied in real water samples for the determination of target analytes. The extraction and preconcentration procedure were performed using the optimized conditions as indicated in Sect. 2.6. Figure 1 illustrate the schematic diagram summarizing the procedure used for extraction and preconcentration of target analytes from real samples.

\section{Results and discussion}

Characterization of the synthesized materials Fourier transform infrared spectroscopy

The chemical properties of the synthesized materials were confirmed by FTIR spectroscopy, and the spectra are shown in Fig. 2a and b. Figure 2a shows the spectra of AC, PABA and magnetic nanoparticles (magnetite), while Fig. 2b shows the spectra of PABA@AC and $\mathrm{Fe}_{3} \mathrm{O}_{4} @ \mathrm{PABA} / \mathrm{AC}$ nanocomposite. The FTIR spectrum of PABA shows the absorption bands at $3408 \mathrm{~cm}^{-1}$ was assigned to the overlapping stretching vibrations of carboxylic $\mathrm{O}-\mathrm{H}$ and secondary amine $\mathrm{N}-\mathrm{H}$, while the bands at 1750,1589 , and $1483 \mathrm{~cm}^{-1}$ were ascribed to the stretching vibrations of $\mathrm{C}=\mathrm{O}, \mathrm{COO}^{-}$asymmetric stretch and $-\mathrm{COO}^{-}$symmetric stretch of the carboxylic group, 

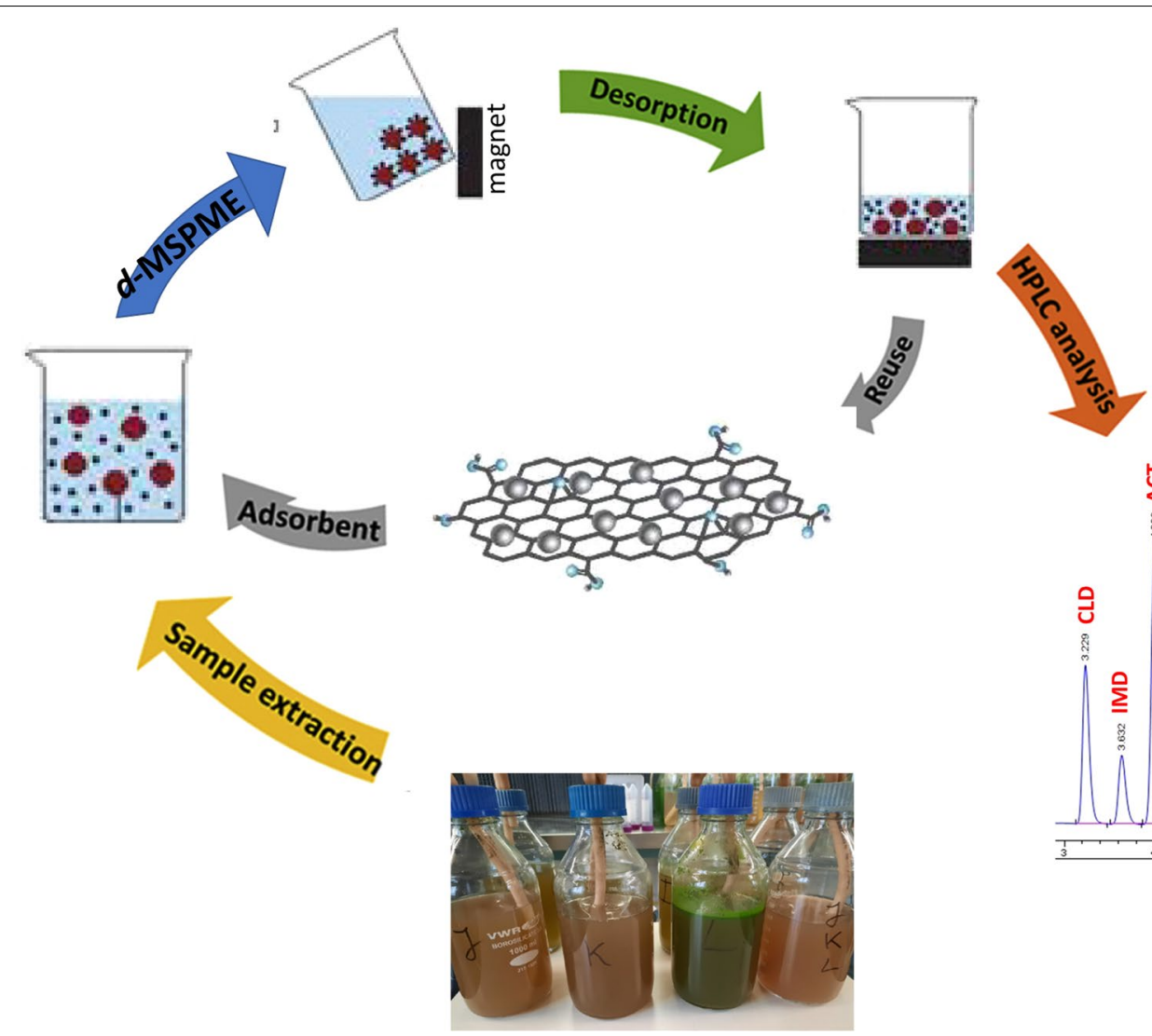

Fig. 1 Schematic diagram summarizing the experimental procedures
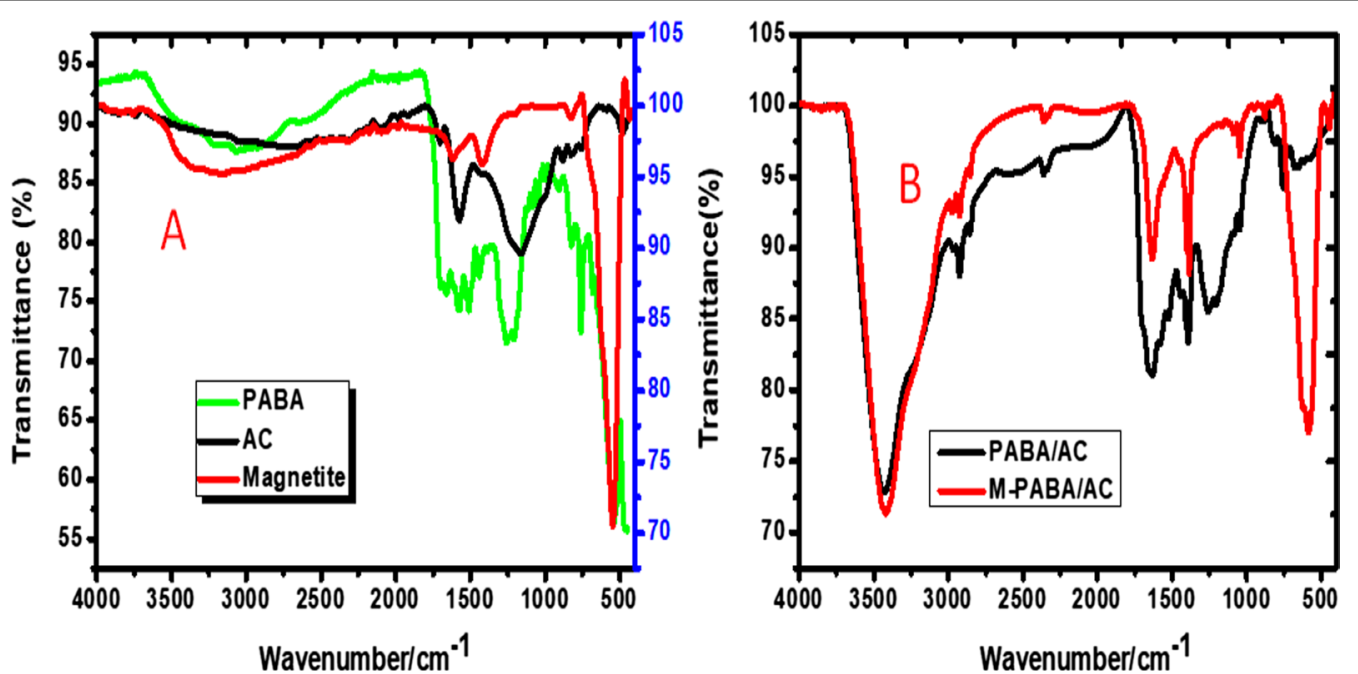

Fig. 2 FTIR spectra indicating the functional groups and characteristic bonds of the as-synthesized materials. Magnetite refers to $\mathrm{Fe}_{3} \mathrm{O}_{4}$ nanoparticles 
respectively. The FTIR spectrum of PABA was similar to the one reported by Zare et al. (2018). The FTIR spectrum of the AC exhibited a broad peak around $3100 \mathrm{~cm}^{-1}$ which was attributed to the vibration of the surface alcoholic $\mathrm{OH}$ or phenolic $\mathrm{OH}$ groups. The incorporation of PABA on AC matrix resulted on the upward shift of the peak that was observed in FTIR spectrum of AC to s $3500 \mathrm{~cm}^{-1}$ (Fig. 2a). The AC spectrum shows absorption peaks at 1627,1550 and $1390 \mathrm{~cm}^{-1}$ indicating the stretching vibration of $\mathrm{C}=\mathrm{O}$, the skeletal vibration of $\mathrm{C}=\mathrm{C}$ and $\mathrm{C}=\mathrm{OH}$ vibration, respectively (Mashile et al. 2018a). Magnetic nanoparticles spectrum showed the main intense asymmetrical peak at around $571 \mathrm{~cm}^{-1}$ corresponding to the $\mathrm{Fe}-\mathrm{O}$ stretching vibrations (Tarhan et al. 2020). In Fig. 2b, the FTIR spectrum of PABA/AC exhibited a strong peak at $3448 \mathrm{~cm}^{-1}$ associated to the stretching vibration of $\mathrm{O}-\mathrm{H} / \mathrm{N}-\mathrm{H}$ groups. The two small peaks at $2920 \mathrm{~cm}^{-1}$ and $2851 \mathrm{~cm}^{-1}$ represented the symmetric and asymmetric stretching of $\mathrm{C}-\mathrm{H}$ bond (Awual et al. 2019; Naushad et al. 2019). The band at $1751 \mathrm{~cm}^{-1}$ was associated with the stretching vibration of $\mathrm{C}=\mathrm{O}$ from carboxylic group. In addition, the amide groups stretching vibrations were observed at $1660 \mathrm{~cm}^{-1}$ showing the polymer bending on AC surface. The peaks at $1440 \mathrm{~cm}^{-1}$ and $1090 \mathrm{~cm}^{-1}$ indicated the stretching vibrations of $\mathrm{N}-\mathrm{H}$ and $\mathrm{C}-\mathrm{N}$, respectively (Njoku et al. 2014), confirming the successful doping of PABA polymer on AC. The spectrum of $\mathrm{Fe}_{3} \mathrm{O}_{4} @ \mathrm{PABA} / \mathrm{AC}$ exhibited Fe-O stretching vibration peak at $571 \mathrm{~cm}^{-1}$ confirming the successful incorporation of magnetic nanoparticles in to the PABA/AC composite (Feng et al. 2020). Additionally, the disappearance of the peak at $1250 \mathrm{~cm}^{-1}$ was a sign of successful doping of iron oxide nanoparticles.

\section{$X$-ray diffraction spectroscopy}

The XRD patterns for magnetite $\left(\mathrm{Fe}_{3} \mathrm{O}_{4}\right.$ nanoparticles), AC, PABA, PABA/AC and $\mathrm{Fe}_{3} \mathrm{O}_{4} @ \mathrm{PABA} / \mathrm{AC}$ nanocomposite are shown in Fig. 3. The XRD pattern of PABA exhibited a broad peak at $2 \theta$ angle of $26^{\circ}$ which is an indication of the amorphous nature of PABA polymer, and it agreed with the recently reported XRD pattern of polyaniline (Mashao et al. 2019). Magnetic nanoparticles exhibited the main diffraction peaks at $2 \theta$ angle of 30.2, 35.4, 43.2, 53.6, 57.1, 62.9 and 74.3, which corresponded with (220), (311), (400), (422), (511), (440) and (533) $h k l$ values, respectively. Additionally, these peaks matched with the reflections proposed by Bragg based on the spinel ferrite structure (Hammad et al. 2020). The broad peaks appeared at $2 \theta$ of $10^{\circ}-30^{\circ}$ and $30^{\circ}-50^{\circ}$ were the characteristic peaks of amorphous $\mathrm{AC}$, matching (022) and (100) graphitic carbon diffraction pattern (Du et al. 2020; Wang et al. 2019). In the PABA/AC composite, the broad peak of PABA was still observed indicating that the PABA polymer sat on AC clusters. In the nanocomposite $\left(\mathrm{Fe}_{3} \mathrm{O}_{4} @ \mathrm{PABA} / \mathrm{AC}\right)$, it was observed that the magnetic nanoparticles were immobilized on the PABA/ AC composite surface. Furthermore, some of the magnetite diffraction peaks were maintained but their intensities decreased proving the successful incorporation of magnetic nanoparticles onto the surface of PABA/AC. It should be noted that there are similarities in the XRD patterns of $\mathrm{Fe}_{3} \mathrm{O}_{4}$ and $\mathrm{Fe}_{3} \mathrm{O}_{4} @ \mathrm{PABA} / \mathrm{AC}$, and this was expected because the crystallinity of magnetite influences the morphology of the composite. However, it is worth mentioning that the XRD patterns of $\mathrm{Fe}_{3} \mathrm{O}_{4} @ \mathrm{PABA} / \mathrm{AC}$ had reduced peak intensities compared to XRD spectrum of magnetite indicating a successful incorporation of $\mathrm{Fe}_{3} \mathrm{O}_{4}$ on PABA/AC surface.

\section{Brunauer-Emmet-Teller}

The surface area and pores of the synthesized materials were obtained using Brunauer-Emmett-Teller (BET) technique based on $\mathrm{N}_{2}$ adsorption-desorption, and the results are presented in Table 2.
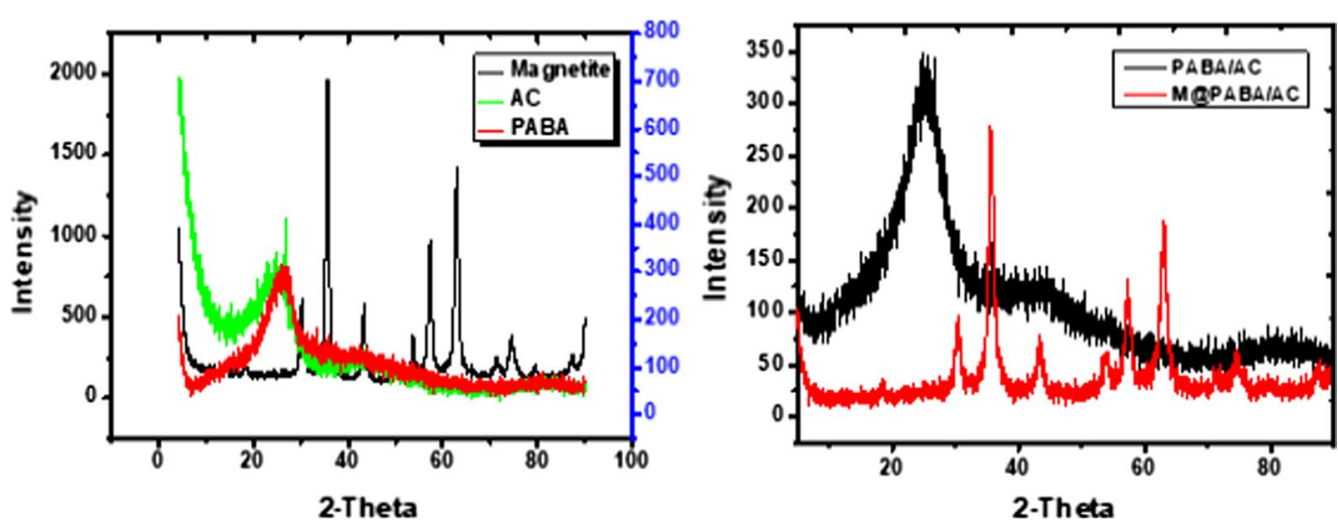

Fig. 3 XRD patterns showing the crystallographic structure of the as-synthesized materials. Magnetite refers to $\mathrm{Fe}_{3} \mathrm{O}_{4}$ nanoparticles 
Table 2 Surface properties of the as-synthesized materials obtained by BET analysis

\begin{tabular}{lllc}
\hline Materials & $\begin{array}{l}\text { Surface area } \\
\left(\mathbf{m}^{\mathbf{2}} \mathbf{g}^{-\mathbf{1}}\right)\end{array}$ & $\begin{array}{l}\text { Pore volume } \\
\left(\mathbf{c m}^{\mathbf{2}} \mathbf{g}^{-\mathbf{1}}\right)\end{array}$ & $\begin{array}{l}\text { Pore } \\
\text { diameter } \\
\mathbf{( n m})\end{array}$ \\
\hline $\mathrm{AC}$ & 1075 & 0.1 & 2.2 \\
$\mathrm{PABA} / \mathrm{AC}$ & 29.9 & 0.094 & 12.6 \\
$\mathrm{Fe}_{3} \mathrm{O}_{4} @ \mathrm{PABA} / \mathrm{AC}$ & 149.68 & 0.30 & 8.0 \\
\hline
\end{tabular}

It should be noted from Table 2 that the surface properties of the AC decreased dramatically after the incorporation of PABA. This could be due to the increase in the diameter of the PABA/AC which results in a decreased in surface area (Sadeghi et al. 2018). In addition, the lower amount of AC doped could also be the cause for surface properties decrease. A significant increase in surface area and pores was observed in the $\mathrm{Fe}_{3} \mathrm{O}_{4} @ \mathrm{PABA} /$ $\mathrm{AC}$ composite after the incorporation of $\mathrm{Fe}_{3} \mathrm{O}_{4}$ nanoparticles. This could further confirm that $\mathrm{Fe}_{3} \mathrm{O}_{4}$ nanoparticles played a crucial role in neonicotinoids extraction by reducing the diameter of the PABA/AC composite, which in turn increases its surface area. The observed surface area and pores were enough for the maximum extraction of the neonicotinoids.

\section{Scanning electron microscopy}

Figure 4 shows the external morphologies and elemental composition of PABA/AC and $\mathrm{Fe}_{3} \mathrm{O}_{4} @ \mathrm{PABA} / \mathrm{AC}$ obtained using SEM/EDS. In the PABA/AC composite (Fig. 4a), PABA covered the surface of the porous AC. Furthermore, the $\mathrm{AC}$ clusters were minimized and were heterogeneously mixed with PABA matrix (Hasan et al. 2019). After the incorporation of $\mathrm{Fe}_{3} \mathrm{O}_{4}$ into the composite (Fig. 4c), pores were reduced. In addition, the coated $\mathrm{Fe}_{3} \mathrm{O}_{4}$ resulted in a smooth surface and reduced particles. The EDS spectrum (Fig. 4b) revealed the presence of oxygen and carbon in PABA/AC as the important elements of the nanocomposite. Chlorine and iron observed were from the oxidizing agent from PABA polymerization. After the incorporation of $\mathrm{Fe}_{3} \mathrm{O}_{4}$ (Fig. 4d), the weight percentage of iron increased drastically confirming the presence of $\mathrm{Fe}_{3} \mathrm{O}_{4}$ in the $\mathrm{Fe}_{3} \mathrm{O}_{4} @ \mathrm{PABA} / \mathrm{AC}$ composite.

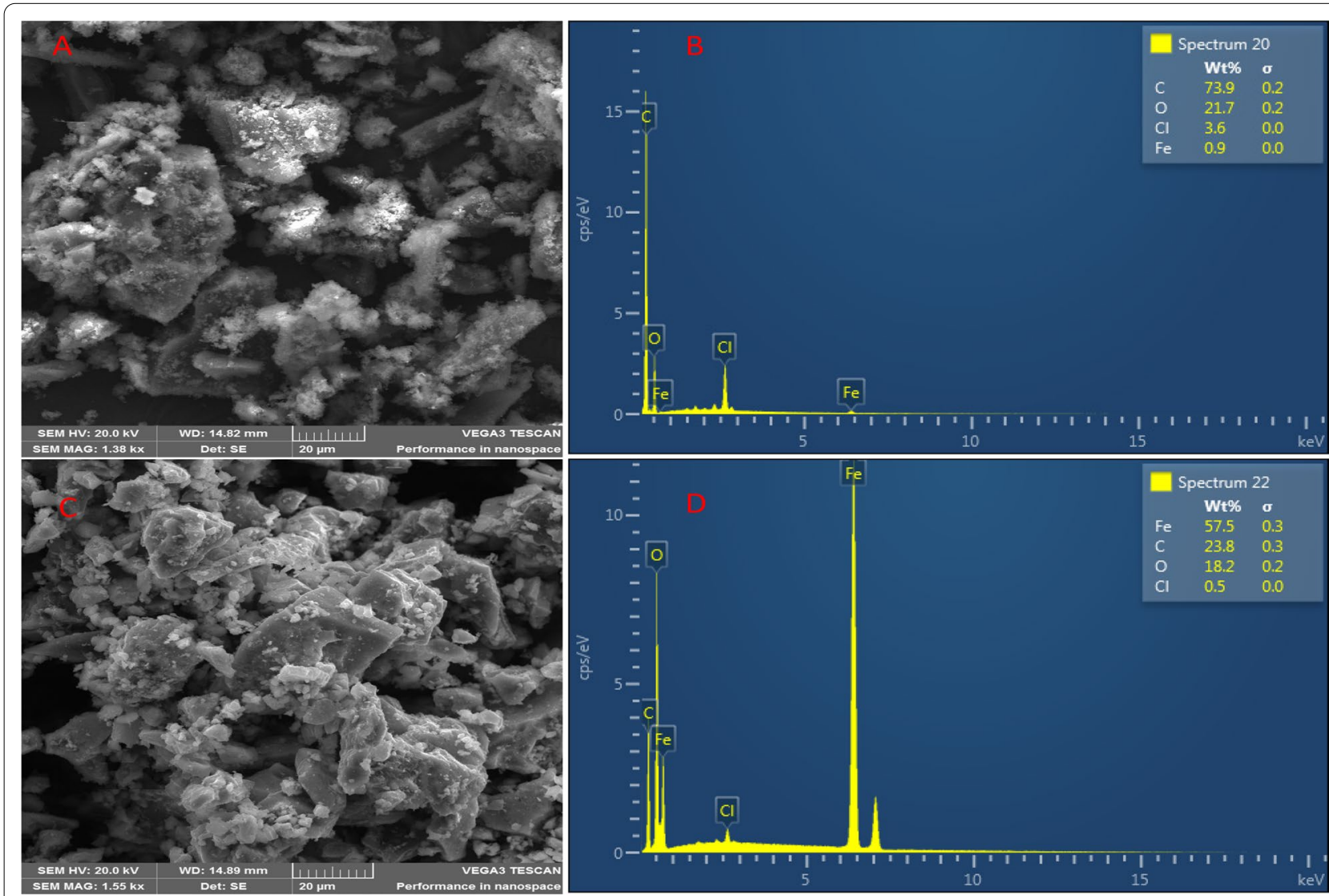

Fig. 4 SEM images indicating the external morphologies of PABA/AC (a), $\mathrm{Fe}_{3} \mathrm{O}_{4} @ P A B A / A C(\mathbf{c})$ and EDS spectrum of PABA/AC (b) and Fe $\mathrm{O}_{4} @ P A B A /$ AC (D) 


\section{Transmission electron microscopy}

The internal morphological features of the synthesized materials were investigated using TEM analysis, and the images are shown in Fig. 5. The TEM image of PABA was similar to the previously reported image by Ramohlola et al. 2017a. In Fig. 5a, it should be observed that PABA sat on AC clusters. In the composite (Fig. 5b), $\mathrm{Fe}_{3} \mathrm{O}_{4}$ nanoparticles distributed dependently mostly on PABA surface owing to their affinity towards the groups that are abundant on the polymer. The agglomeration observed is caused by poor dispersibility of the $\mathrm{Fe}_{3} \mathrm{O}_{4}$ nanoparticles.

\section{Optimization of the developed $d$-MSPME}

\section{Screening of $d$-MSPME preconcentration procedure using} central composite design

To obtain best results from any analytical method, screening process was conducted to investigate the most influential parameters in the extraction and preconcentration of neonicotinoids. A two-level $\left(2^{5-1}\right)$ FFD was employed as a chemometric tool for the screening of $d$-MSPME method. In this work, five parameters including $\mathrm{pH}$, extraction time (ET), mass of adsorbent (MA), eluent volume (EV) and desorption time (DT) were optimized. Twenty experiments were conducted for screening and the results were recorded as percentage recoveries (Additional file 1: Table S1). The evaluation of the experimental data was done using analysis of variance (ANOVA), and the ANOVA results were recorded as Pareto charts (Fig. 6a-d). Pareto charts allowed the assessment of the main and interactive effects. The length of each bar in Fig. 6 represented the effects of individual factors and their interactions, and these bars are proportional to the effect of each factor or interactions. If the bar length surpasses the reference line, it implies that the factor or interaction has significant effect on the analytical response at 95\% confidence level (Biata et al. 2017).
As shown in Fig. 6a, b and d, mass of adsorbent and eluent volume were influential on analytical response for ACT, IMD and CLD, except for extraction and preconcentration of TCL where only EV was significant at 95\% confidence level. Moreover, the interaction between MA and EV (2by3) was statistically significant. Ideally, the eluent volume must be sufficient to quantitatively extract the all the analytes from the surface of the adsorbent. In addition, enough adsorbent is required to adsorb the target analytes. Therefore, both MA and EV should be sufficient to achieve quantitative adsorption and elution of the analytes, respectively. The two factors (MA and EV) were further optimized using $C C D$ to minimize the number of experiments and to investigate their interactions based on the quadratic model employed on response surface methodologies (RSM) (Li et al. 2019).

\section{Further optimization}

The preliminary studies indicated that the $\mathrm{Fe}_{3} \mathrm{O}_{4} @ \mathrm{PABA} /$ $\mathrm{AC}$ was capable of adsorbing and desorbing the neonicotinoid insecticides. The factors that were affecting the performance of $d$-MSPME method were further investigated. These factors include MA and EV, and were optimized using CCD involving ten experiments, to evaluate their interacting effects with respect to the extraction recoveries (Additional file 1: Table S2). The interactive effects, main effects and quadratic effects towards the extraction of the neonicotinoids were investigated by the RSM based on CCD (Ferreira et al. 2019), and the results are presented as 3D surface plots in Fig. 7. The interactions between the factors were significant towards the extraction of IMD and CLD. Higher extraction recoveries were observed at higher MA and EV. However, the interactions of the factors towards the extraction of ACT and TLC did not show any statistical significance. The best precise conditions could not be assumed from the plots

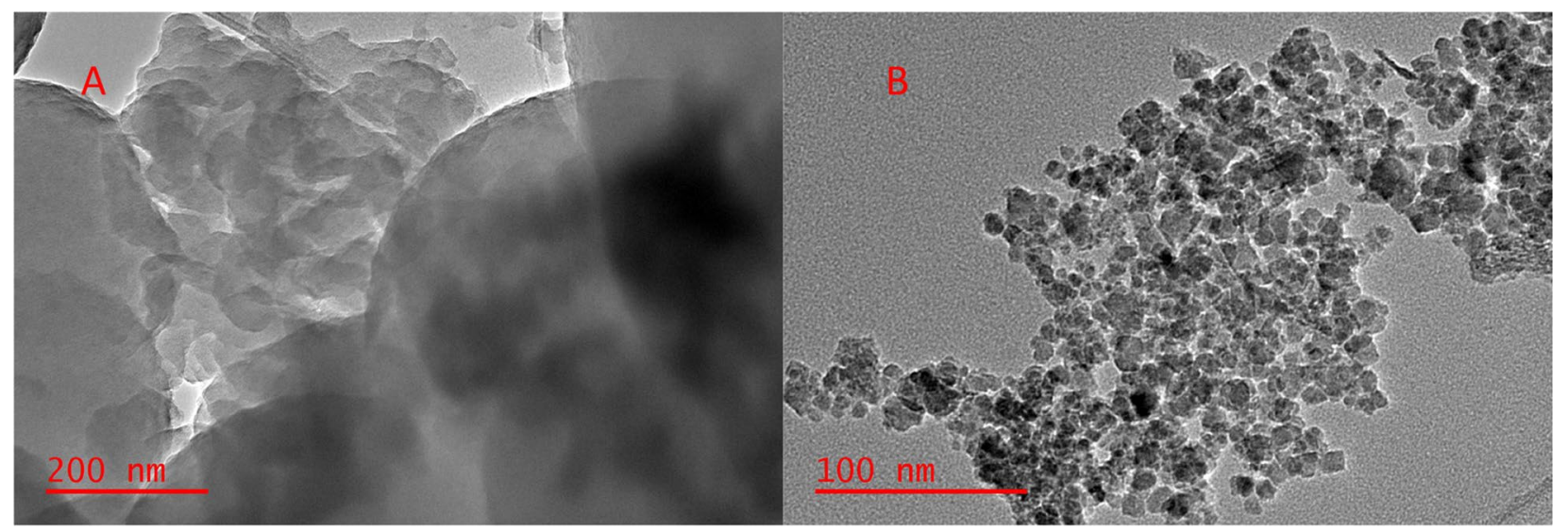

Fig. 5 TEM images indicating the internal morphologies of $\mathbf{a} P A B A / A C$ and $\mathbf{b} \mathrm{Fe}_{3} \mathrm{O}_{4} @ P A B A / A C$ 

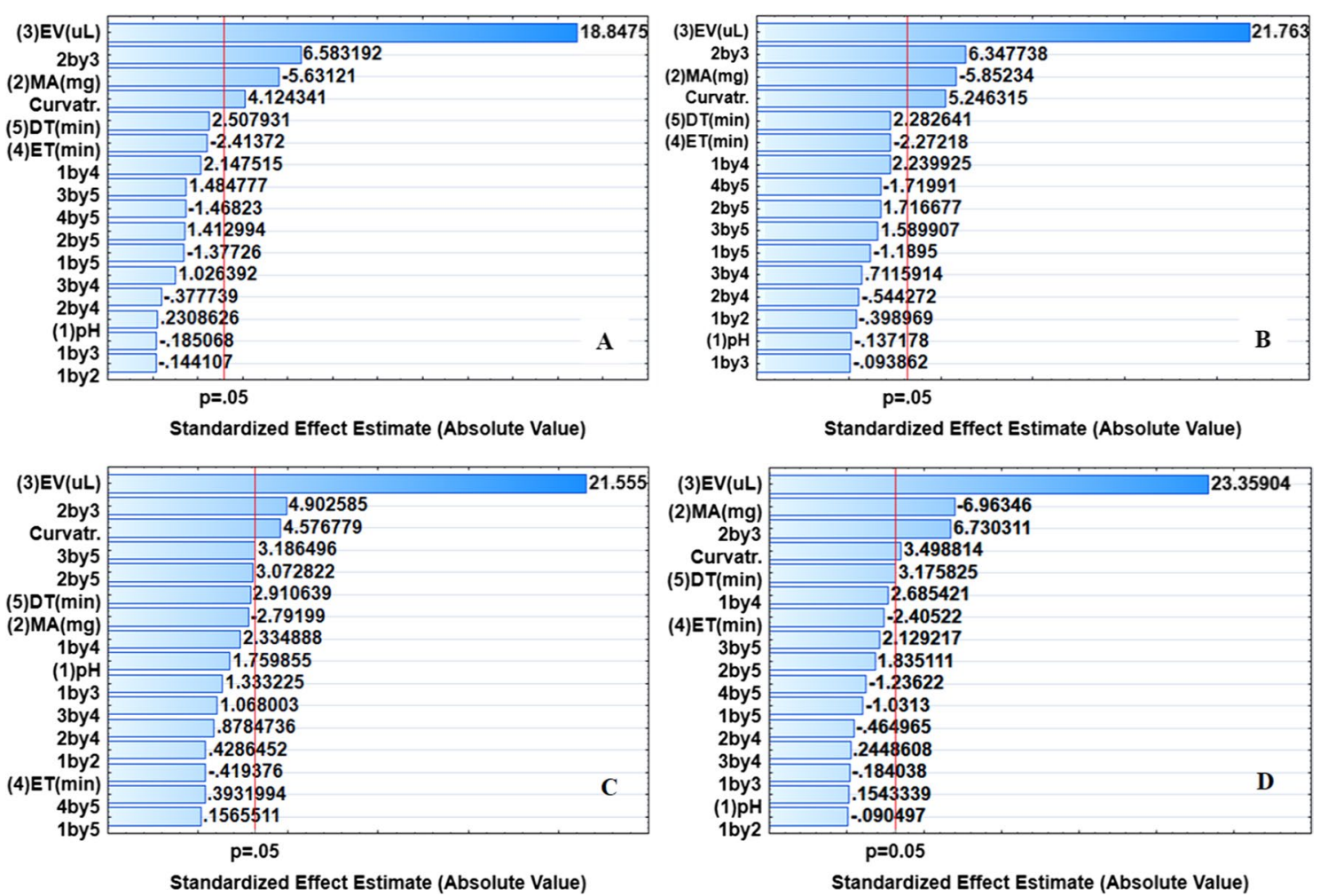

Fig. 6 Pareto charts indicating the effect of factors on extraction and preconcentration of a acetamiprid (ACT), b imidacloprid (IMD), c thiacloprid (TCL) and $\mathbf{d}$ clothianidin (CLD) using magnetic-based PABA activated carbon adsorbent. ET extraction time, MA mass of adsorbent, EV eluent volume (EV) and DT desorption time. 1by2: interaction between $\mathrm{pH}$ and MA; 1 by3: interaction between $\mathrm{pH}$ and EV; 1 by4: interaction between $\mathrm{pH}$ and $\mathrm{ET}$; 1by5: interaction between $\mathrm{pH}$ and DT; 2by3: interaction between MA and EV; 2by4: interaction between MA and ET; 2by5: interaction between MA and DT; 3by4: interaction between EV and ET; 3by5: interaction between EV and DT; 4by5: interaction between ET and DT

since the plots give the region not the precise points. Therefore, the desirability profiles were obtained by further optimization owing to their potential to pinpoint exact optimum values (Mashile et al. 2018b).

Figure 8 shows the desirability profiles of the thiacloprid obtained by the conversion of the responses into the dimensionless values called desirability by the application of statistical design. The aggregation of these individual desirability $\left(d_{i}\right)$ are then utilized to obtain the overall desirability (Valasques et al. 2019; Bruns et al. 2006). According to the literature, desirability ranges from 0 (undesirable), 0.5 (partially desirable) and 1 (desirable) (Bezerra et al. 2019). Figure 8 also illustrates the individual desirability scores for the extraction and preconcentration of the target analytes (bottom), and the desirability value of 1.0 was selected to obtain optimum conditions. The percent recovery obtained from plots for each factor is presented at the top left-hand side. According to Mashile et al. 2018b, the figures on the top lefthand side demonstrate the changes in the level of each individual variable, analytical response, and the overall desirability. It can be seen from the desirability profile that both factors were considered significant since the lower points of these factors deviated from the desirable line indicating that a change in one of these values can cause dramatic effect on analytical responses (\% extraction recoveries). The desirability profiles for the other three neonicotinoids showed similar results (Additional file 1: Fig. S1). The optimum conditions predicted from these desirability profiles and RSM were $41 \mathrm{mg}$ for MA and $1200 \mu \mathrm{L}$ for EV. The use of small MA for the extraction of the selected neonicotinoids in a short period of time has proved that the $\mathrm{Fe}_{3} \mathrm{O}_{4} @ \mathrm{PABA} / \mathrm{AC}$ adsorbent could be potentially applied in a wide range of sample preparation procedures including their miniaturized versions. Other parameters that were not significant in the screening process were kept constant at $10 \mathrm{~min}, 5 \mathrm{~min}$ and 6.5 for ET, DT, and $\mathrm{pH}$, respectively.

\section{Method validation}

Under optimum conditions, the analytical performance of the developed $d$-MSPME procedure was assessed in terms of limits of detection (LOD), quantification (LOQ), linearity, repeatability and reproducibility (Table 3 ). The 

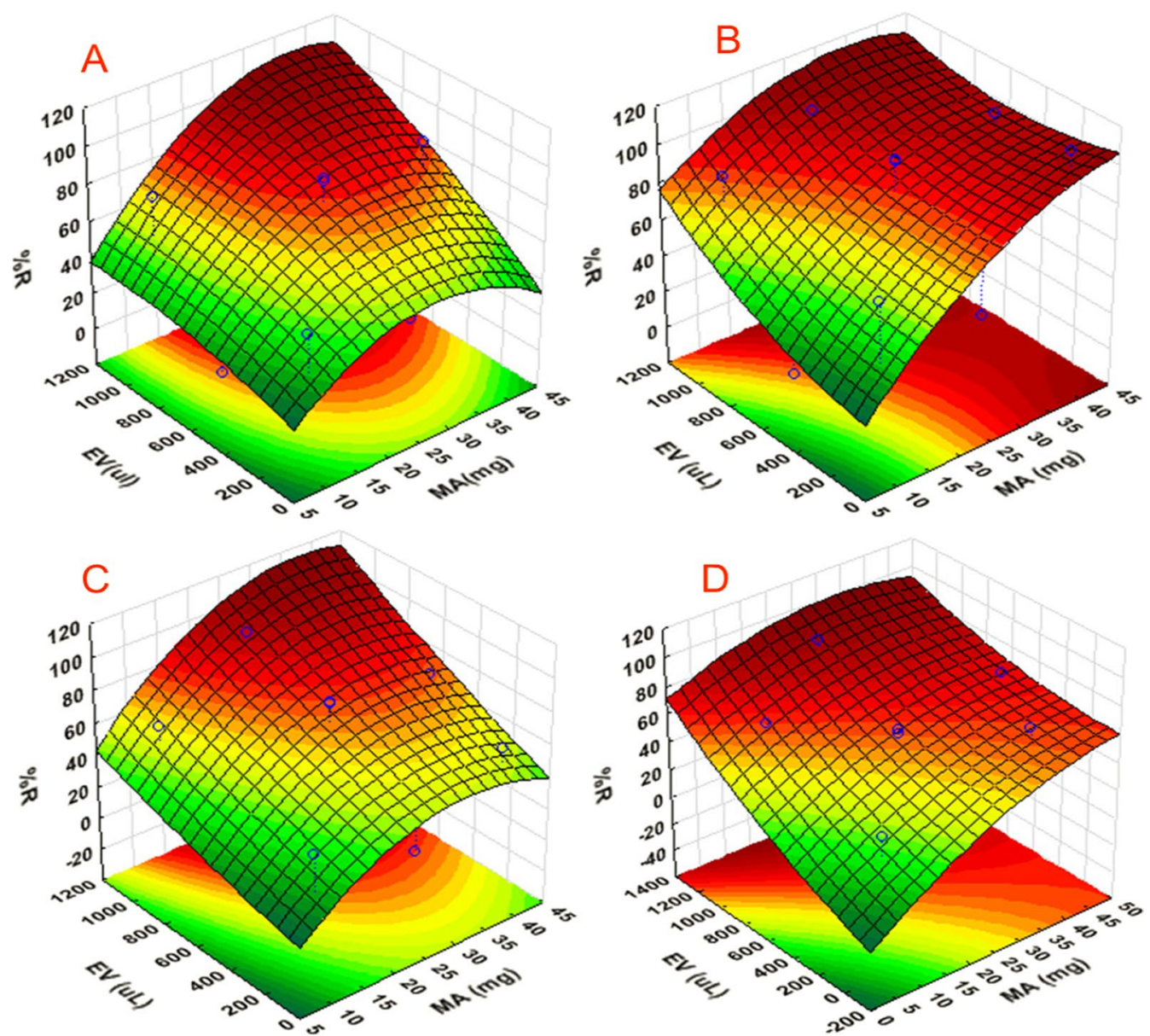

Fig. 7 Three-dimensional contour plots of a acetamiprid (ACT), b imidacloprid (IMD), $\mathbf{c}$ thiacloprid (TCL) and $\mathbf{d}$ clothianidin (CLD) describing the combined interactive effects of investigated factors (EV eluent volume, $M A$ mass of adsorbent) on the analytical response

neonicotinoids standard solutions ranging from concentrations of $0-700 \mu \mathrm{g} \mathrm{L} \mathrm{L}^{-1}$ were preconcentrated using the $d$-MSPME and the calibration curve for each analyte was constructed. From the calibration curves, the linearity was from 1.4 to $700 \mu \mathrm{g} \mathrm{L} \mathrm{L}^{-1}$ with the correlation coefficients ranging from 0.9941 to 0.9987 , respectively, which indicates good linearity. The LOD and LOQ were demonstrated based on the International Union of Pure and Applied Chemistry (IUPAC) as the lowest amounts of the analytes that can give responses equivalent to 3.0 or 10 times the original signals, respectively. They are expressed as the ratio of the standard deviation to the slope of the calibration curve (Mpupa et al. 2019; Komendova 2020). The LODs ranged from 0.41 to $0.82 \mu \mathrm{g} \mathrm{L}^{-1}$, while LOQs were between 1.4 and $2.7 \mu \mathrm{g} \mathrm{L}^{-1}$. The repeatability (intra-day) and reproducibility (inter-day) procedures were conducted to assess the precision of the method. These were expressed in terms of relative standard deviations (\%RSD) based on ten replicates on the same day (repeatability, $n=10$ ) and five different days (reproducibility, $n=5$ working days). The intra-day precisions were found to be less than $1 \%$, while the inter-day precisions were less than $6 \%$ (Table 3 ).

\section{Adsorbent reusability}

The attractive feature of an exceptional adsorbent includes high regeneration and reusability. This allows the reduction in the overall cost of the adsorption technology. Additionally, for economic reasons, the desorption of the analyte from an adsorbent is considered as significant approach to the reuse of spent adsorbents. In this study, the reusability studies were carried to determine the number of cycles a spent $\mathrm{Fe}_{3} \mathrm{O}_{4} @ \mathrm{PABA} / \mathrm{AC}$ nanocomposite can be used for the preconcentration of the neonicotinoids while maintaining maximum extraction recoveries. As seen in Additional file 1, Fig. S2, quantitative recoveries $(\geq 80 \%)$ for all neonicotinoids were obtained when the adsorbent was used for at least 10 times with the \%RSD ranging from 2.5 to $3.1 \%$. Even though the adsorption efficiency decrease was observed, 


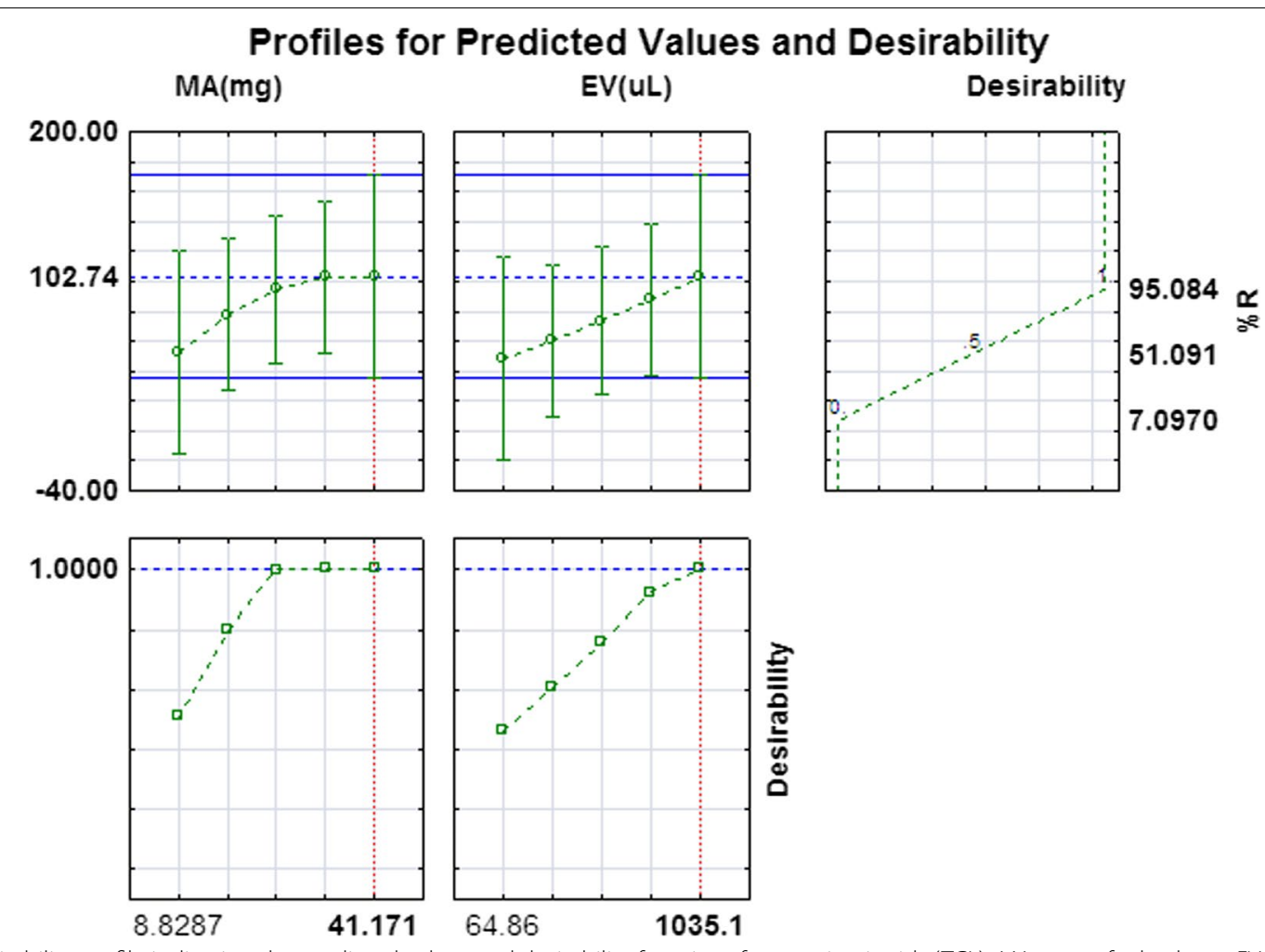

Fig. 8 Desirability profile indicating the predicted values and desirability functions for neonicotinoids (TCL). MA mass of adsorbent, EV eluent volume

the spent adsorbent showed better stability and reusability. Therefore, it can be concluded that $\mathrm{Fe}_{3} \mathrm{O}_{4} @ \mathrm{PABA} / \mathrm{AC}$ nanocomposite had acceptable regeneration and reusability performances and can be viewed as a promising adsorbent for efficient extraction and preconcentration of various organic pollutants in water systems.

\section{Application to real samples}

The reliability of the $d$-MSPME method was conducted using the spike recovery tests. These tests were carried at two levels, $1.0 \mu \mathrm{g} \mathrm{L}^{-1}$ (lower level) and $5.0 \mu \mathrm{g} \mathrm{L}^{-1}$ (higher level) for all analytes (Table 4). It was clearly observed that the analytes of interest were not detected in all

Table 3 Analytical performance of the developed method

\begin{tabular}{lllll}
\hline Parameters & ACT & IMD & TCL & CLD \\
\hline Linearity & $1.8-700$ & $2.6-700$ & $1.4-700$ & $2.7-700$ \\
Correlation coefficient (R2) & 0.9941 & 0.9982 & 0.9933 & 0.9987 \\
LOD $\left.(\mu \mathrm{g} \mathrm{L})^{1}\right)$ & 0.54 & 0.77 & 0.41 & 0.82 \\
LOQ $\left(\mu \mathrm{g} \mathrm{L}^{1}\right)$ & 1.8 & 2.6 & 1.4 & 2.7 \\
Inter-day precision (\%RSD) & 0.46 & 0.35 & 0.75 & 0.55 \\
Inter-day precision \%RSD & 3.7 & 3.0 & 5.5 & 1.7 \\
\hline
\end{tabular}

ACT Acetamiprid, IMD imidacloprid, TCL thiacloprid, CLD clothianidin matrices (influent, effluent, and river water samples). The spiking process was done due to the absence of the certified reference material (CRM) for neonicotinoids. Each sample was analysed three times, and the response was obtained from the average of the outcomes. Maximum percentage recoveries (\%R) were still obtained in the ranges of 86.7 and $99.2 \%$ for all analytes in all matrices, indicating that the matrices had no disadvantageous effects on extraction of the neonicotinoids. The relative standard deviation was $<5 \%$, further proving that the effects from the matrix were very little for the proposed analytical procedure. The $d$-MSPME analytical method showed potential in extraction and preconcentration of trace neonicotinoids from various environmental wastewater matrices.

\section{Comparison between the current proposed method and others}

The performance of the current analytical method coupled with HPLC-DAD towards the preconcentration of neonicotinoids was compared with the methods reported recently. The parameters of the present proposed method and those of the previously reported methods are summarized in Table 5. The current proposed method had a good repeatability, and the relative standard deviation 
Table 4 Application of the suggested analytical method in real water samples (mean \pm SD)

\begin{tabular}{|c|c|c|c|c|c|c|c|c|c|}
\hline \multirow[t]{2}{*}{ Sample } & \multirow{2}{*}{$\begin{array}{l}\text { Added } \\
\left(\mu \mathrm{g} \mathrm{L}^{-1}\right)\end{array}$} & \multicolumn{2}{|l|}{ ACT } & \multicolumn{2}{|l|}{ IMD } & \multicolumn{2}{|l|}{$\mathrm{TCL}$} & \multicolumn{2}{|l|}{ CLD } \\
\hline & & Found $\left(\mu \mathrm{g} \mathrm{L}^{-1}\right)$ & $\% R$ & Found $\left(\mu \mathrm{g} \mathrm{L}^{-1}\right)$ & $\% R$ & Found ( $\mu \mathrm{g} \mathrm{L}^{-1}$ ) & $\% R$ & Found $\left(\mu \mathrm{g} \mathrm{L}^{-1}\right)$ & $\% R$ \\
\hline \multirow[t]{3}{*}{ Influent } & 0 & ND & - & ND & - & ND & - & ND & - \\
\hline & 1.0 & $0.96 \pm 0.02$ & 96.0 & $0.95 \pm 0.05$ & 95.1 & $0.94 \pm 0.01$ & 94.1 & $0.96 \pm 0.02$ & 95.5 \\
\hline & 5.0 & $4.75 \pm 0.12$ & 95.1 & $4.91 \pm 0.07$ & 98.2 & $4.88 \pm 0.03$ & 97.6 & $4.84 \pm 0.05$ & 96.8 \\
\hline \multirow[t]{3}{*}{ Effluent } & 0 & ND & - & ND & - & ND & - & ND & - \\
\hline & 1.0 & $0.87 \pm 0.02$ & 86.7 & $0.92 \pm 0.03$ & 92.1 & $0.90 \pm 0.02$ & 89.7 & $0.93 \pm 0.01$ & 92.9 \\
\hline & 5.0 & $4.78 \pm 0.15$ & 95.5 & $4.81 \pm 0.12$ & 96.2 & $4.67 \pm 0.11$ & 93.3 & $4.78 \pm 0.12$ & 95.6 \\
\hline \multirow[t]{3}{*}{ River water } & 0 & ND & - & ND & - & ND & - & ND & - \\
\hline & 1.0 & $0.97 \pm 0.02$ & 96.8 & $0.98 \pm 0.03$ & 97.7 & $0.99 \pm 0.04$ & 98.8 & $0.96 \pm 0.01$ & 95.6 \\
\hline & 5.0 & $4.92 \pm 0.11$ & 98.4 & $4.86 \pm 0.05$ & 97.1 & $4.94 \pm 0.14$ & 98.8 & $4.96 \pm 0.05$ & 99.2 \\
\hline
\end{tabular}

ND Not detected

Table 5 Analytical characteristics of the proposed method in comparison with the recently reported methods for the extraction and determination of neonicotinoids in various matrices

\begin{tabular}{|c|c|c|c|c|c|c|}
\hline Analytes & Matrix & Analytical method & Linearity $\left(\mu \mathrm{g} \mathrm{L}^{-1}\right)$ & LODs $\left(\mu g \mathrm{~L}^{-1}\right)$ & $\%$ RSD & References \\
\hline IMD, TCL, CLD & $\begin{array}{l}\text { Surface water, soil, and } \\
\text { urine samples }\end{array}$ & $\begin{array}{l}\text { In-situ metathesis of deep } \\
\text { eutectic solvent/HPLC-UV }\end{array}$ & $1-1000$ & $0.3-1.0$ & $4.27-8.03$ & Kachangoon et al. 2020) \\
\hline ACT, IMD, TCL, CLD & Honey samples & DLLME/L-MS/MS & $1.5-100$ & $0.5-1.0$ & $2.74-11.8$ & Jovanov et al. 2013) \\
\hline$A C T, I M D$ & $\begin{array}{l}\text { Fruit juices and vegeta- } \\
\text { bles }\end{array}$ & RT-ILPME-HPLC-DAD & $0.41-5000$ & $0.12-0.33$ & $4-6$ & Farajzadeh et al. 2016) \\
\hline$A C T, I M D, T C L, C L D$ & Honey liqueur sample & MMC-QuEChERS & $2.5-100$ & $1-2.5$ & $11.3-16.40$ & Jovanov et al. 2014) \\
\hline ACT, IMD, TCL, CLD & $\begin{array}{l}\text { River water, influent, and } \\
\text { effluent }\end{array}$ & $d$-MSPME & $5-700$ & $0.41-0.82$ & $0.35-0.55$ & This method \\
\hline
\end{tabular}

(RSDs) were smaller than those of the recently reported methods. Limits of detection of the presented method were lower than some of the mentioned methods and the linear ranges were reasonably wider. Compared to a relative method reported by Ghiasi et al. (2020) for the preconcentration of neonicotinoids, it can be concluded that the current method is facile, rapid, sensitive, and environmentally friendly towards the extraction and determination of neonicotinoids from various environmental samples. Furthermore, the method was able to provide maximum $\% R$ for four analytes in the presence of the interferences, and the $\% R$ was maintained even after ten successive cycles (Additional file 1: Fig. S2).

\section{Conclusions}

Magnetic-based PABA/AC nanocomposite was successfully synthesized and applied as an adsorbent in the extraction and preconcentration of the selected neonicotinoids (ACT, IMD, TCL and CLD) from model solutions and real water samples. The $d$-MSPME showed a great potential as a preconcentration method for the selected neonicotinoid insecticides. $\mathrm{Fe}_{3} \mathrm{O}_{4} @ \mathrm{PABA} / \mathrm{AC}$ nanocomposite was characterized using FTIR, SEM, TEM, BET and XRD. Before the application of the $d$-MSPME method in the real samples, parameters such as $\mathrm{pH}, \mathrm{ET}$, MA, DT and EV affecting the performance of the method were optimized for the extraction of neonicotinoids from spiked tap water. Under optimum conditions, the reliability of the $d$-MSPME method was evaluated based on LODs and LOQs, which ranged from 0.41 to $0.82 \mu \mathrm{g} \mathrm{L}-1$ and 1.4 to $2.7 \mu \mathrm{g} \mathrm{L}^{-1}$, respectively. $\mathrm{Fe}_{3} \mathrm{O}_{4} @ \mathrm{PABA} / \mathrm{AC}$ showed high reusability which was confirmed by reusing the adsorbent at least 10 times while maintaining maximum recoveries. Furthermore, the adsorbent was used in the extraction of neonicotinoids from real water samples obtained from domestic WWTP. The adsorbent showed magnificent applicability in the neonicotinoids extraction, and this indicated that the nanocomposite might mitigate the global challenge based on monitoring trace organic pollutants in environmental wastewater. 


\section{Supplementary Information}

The online version contains supplementary material available at https://doi. org/10.1186/s40543-021-00311-4.

Additional file 1. Table S1. List of runs obtained from two-level 25-1 fractional factorial design and their responses for screening. Table S2. List of runs obtained from small central composite design (SCCD) and their responses for second optimization. Figure $\mathbf{S 1}$. Desirability profiles of (A) $A C T$, (B) IMD and (C) CLD. Figure $\mathbf{S}$ 2. Percentage recovery vs number of cycles for (A) ACT, (B) IMD, (C) TCL and (D) CLD.

\section{Acknowledgements}

The authors further appreciate the University of Johannesburg for allowing us to utilize their laboratory facilities to make this study possible.

\section{Authors' contributions}

NJW involved in conceptualization, conducting experiments, investigation, writing-original draft, writing-review and editing, experimental design, methodology and interpretation of data. AM involved in conceptualization, writing-review and editing, experimental design, methodology and interpretation of data; SKS involved in conducting experiments, writing-review and editing and interpretation of data. PNN involved in conceptualization, investigation, project administration software, experimental design, writing-review and editing and supervision. All authors read and approved the final manuscript.

\section{Funding}

The authors would like to give thanks to the National Nanoscience Postgraduate Teaching and Training Platform (NNPTTP) for financial support and National Research Foundation (NRF, South Africa, Grant No. 99270\&91230).

\section{Availability of data and materials}

Not applicable.

\section{Declarations}

\section{Competing interests}

There are no competing interests associated with this study.

\section{Author details}

'Department of Chemical Sciences, University of Johannesburg, Doornfontein Campus, P.O. Box 17011, Johannesburg 2028, South Africa. ${ }^{2}$ Department of Science and Innovation-National Research Foundation South African Research Chair Initiative (DSI-NRF SARChI): Nanotechnology for Water, University of Johannesburg, Doornfontein 2028, South Africa. ${ }^{3}$ DSI/Mintek Nanotechnology Innovation Centre, University of Johannesburg, Doornfontein 2028, South Africa.

Received: 3 July 2021 Accepted: 20 December 2021

Published online: 18 January 2022

\section{References}

Albishri HM, Marwani HM, Batterjee MG, Soliman EM. Eriochrome Blue Black modified activated carbon as solid phase extractor for removal of $\mathrm{Pb}$ (II) ions from water samples. Arab J Chem. 2017;10:S1955-62.

Anzecc A (2000) Australian and New Zealand guidelines for fresh and marine water quality. Australian and New Zealand Environment and Conservation Council and Agriculture and Resource Management Council of Australia and New Zealand, Canberra, pp 1-103.

Arase S, Horie K, Kato T, Noda A, Mito Y, Takahashi M, Yanagisawa T. Intelligent peak deconvolution through in-depth study of the data matrix from liquid chromatography coupled with a photo-diode array detector applied to pharmaceutical analysis. J Chromatogr A. 2016;1469:35-47.

Arnnok P, Patdhanagul N, Burakham R. Dispersive solid-phase extraction using polyaniline-modified zeolite $\mathrm{NaY}$ as a new sorbent for multiresidue analysis of pesticides in food and environmental samples. Talanta. 2017:164:651-61.
Awual MR, Hasan MM, Islam A, Rahman MM, Asiri AM, Khaleque MA, Sheikh MC. Introducing an amine functionalized novel conjugate material for toxic nitrite detection and adsorption from wastewater. J Clean Prod. 2019;228:778-85

Azzouz A, Kailasa SK, Lee SS, Rascón AJ, Ballesteros E, Zhang M, Kim K-H. Review of nanomaterials as sorbents in solid-phase extraction for environmental samples. TrAC Trends Anal Chem. 2018;108:347-69.

Bezerra MA, Ferreira SLC, Novaes CG, dos Santos AMP, Valasques GS, da Mata Cerqueira UMF, dos Santos Alves JP. Simultaneous optimization of multiple responses and its application in analytical chemistry - a review. Talanta. 2019;194:941-59.

Biata NR, Nyaba L, Ramontja J, Mketo N, Nomngongo PN. Determination of antimony and tin in beverages using inductively coupled plasma-optical emission spectrometry after ultrasound-assisted ionic liquid dispersive liquid-liquid phase microextraction. Food Chem. 2017;237:904-11.

Biswas A, Patra AK, Sarkar S, Das D, Chattopadhyay D, De S. Synthesis of highly magnetic iron oxide nanomaterials from waste iron by one-step approach. Colloids Surf A Physicochem Eng Asp. 2020;589:124420.

Bruns RE, Scarminio IS, de Barros Neto B. Statistical design-chemometrics, vol. 25. Amsterdam: Elsevier; 2006.

Chisvert A, Cárdenas S, Lucena R. Dispersive micro-solid phase extraction. TrAC Trends Anal Chem. 2019;112:226-33.

Dimpe KM, Ngila J, Nomngongo PN. Preparation and application of a tyrebased activated carbon solid phase extraction of heavy metals in wastewater samples. Phys Chem Earth Parts a/b/c. 2018;105:161-9.

Du H, Cheng J, Wang M, Tian M, Yang X, Wang Q. Red dye extracted sappan wood waste derived activated carbons characterization and dye adsorption properties. Diam Relat Mater. 2020;102:107.

Ebrahimi B, Mohammadiazar S, Ardalan S. New modified carbon based solid phase extraction sorbent prepared from wild cherry stone as natural raw material for the pre-concentration and determination of trace amounts of copper in food samples. Microchem J. 2019;147:666-73.

Farajzadeh MA, Bamorowat M, Mogaddam MRA. Ringer tablet-based ionic liquid phase microextraction: application in extraction and preconcentration of neonicotinoid insecticides from fruit juice and vegetable samples. Talanta. 2016:160:211-6.

Feng Z, Chen H, Li H, Yuan R, Wang F, Chen Z, Zhou B. Preparation, characterization, and application of magnetic activated carbon for treatment of biologically treated papermaking wastewater. Sci Total Environ. 2020;713:136

Ferreira SL, Junior MMS, Felix CS, da Silva DL, Santos AS, Neto JHS, de Souza CT, Junior RAC, Souza AS. Multivariate optimization techniques in food analysis - a review. Food Chem. 2019;273:3-8.

Furman OS, Teel AL, Watts RJ. Mechanism of base activation of persulfate. Environ Sci Technol. 2010;44:6423-8.

Georgakopoulos P, Zachari R, Mataragas M, Athanasopoulos P, Drosinos EH, Skandamis PN. Optimisation of octadecyl (C18) sorbent amount in QuEChERS analytical method for the accurate organophosphorus pesticide residues determination in low-fatty baby foods with response surface methodology. Food Chem. 2011;128:536-42.

Ghiasi A, Malekpour A, Mahpishanian S. Metal-organic framework MIL 101 ( $\mathrm{Cr}$ )- $\mathrm{NH}_{2}$ functionalized magnetic graphene oxide for ultrasonic-assisted magnetic solid phase extraction of neonicotinoid insecticides from fruit and water samples. Talanta. 2020;217:121120.

Ghouas H, Haddou B, Kameche M, Canselier J-P, Gourdon C. Removal of tannic acid from aqueous solution by cloud point extraction and investigation of surfactant regeneration by microemulsion extraction. J Surfactants Deterg. 2016;19:57-66.

Giakisikli G, Anthemidis AN. Magnetic materials as sorbents for metal/metalloid preconcentration and/or separation. A review. Anal Chim Acta. 2013;789:1-16

Guo H, Zhou X, Zhang Y, Yao Q, Qian Y, Chu H, Chen J. Carbamazepine degradation by heterogeneous activation of peroxymonosulfate with lanthanum cobaltite perovskite: performance, mechanism and toxicity. J Environ Sci. 2020;91:10-21.

Hammad M, Hardt S, Mues B, Salamon S, Landers J, Slabu I, Wende H, Schulz C, Wiggers H. Gas-phase synthesis of iron oxide nanoparticles for improved magnetic hyperthermia performance. J Alloys Compd. 2020;824:153.

Hasan M, Rashid MM, Hossain MM, Al Mesfer MK, Arshad M, Danish M, Lee M, El Jery A, Kumar N. Fabrication of polyaniline/activated carbon composite 
and its testing for methyl orange removal: optimization, equilibrium, isotherm and kinetic study. Polym Test. 2019;77:105.

Ike IA, Linden KG, Orbell JD, Duke M. Critical review of the science and sustainability of persulphate advanced oxidation processes. Chem Eng J. 2018;338:651-69.

Javadi T, Farajmand B, Yaftian MR, Zamani A. Homogenizer assisted dispersive liquid-phase microextraction for the extraction-enrichment of phenols from aqueous samples and determination by gas chromatography. J Chromatogr A. 2020:1614:460733.

Jiang R, Xu J, Lin W, Wen S, Zhu F, Luan T, Ouyang G. Investigation of the kinetic process of solid phase microextraction in complex sample. Anal Chim Acta. 2015;900:111-6.

Jovanov P, Guzsvány V, Franko M, Lazić S, Sakač M, Šarić B, Banjac V. Multi-residue method for determination of selected neonicotinoid insecticides in honey using optimized dispersive liquid-liquid microextraction combined with liquid chromatography-tandem mass spectrometry. Talanta. 2013;111:125-33.

Jovanov P, Guzsvány V, Franko M, Lazić S, Sakač M, Milovanović I, Nedeljković N. Development of multiresidue DLLME and QuEChERS based LC-MS/ MS method for determination of selected neonicotinoid insecticides in honey liqueur. Food Res Int. 2014;55:11-9.

Kachangoon R, Vichapong J, Santaladchaiyakit Y, Srijaranai S. Cloud-point extraction coupled to in-situ metathesis reaction of deep eutectic solvents for preconcentration and liquid chromatographic analysis of neonicotinoid insecticide residues in water, soil and urine samples. Microchem J. 2020;152:104377.

Komendova R. Recent advances in the preconcentration and determination of platinum group metals in environmental and biological samples. TrAC Trends Anal Chem. 2020;122:115708.

Li C, Huang J, Wang K, Chen Z, Liu Q. Optimization of processing parameters of laser skin welding in vitro combining the response surface methodology with NSGA- II. Infrared Phys Technol. 2019;103:103067.

Mahai G, Wan Y, Xia W, Yang S, He Z, Xu S. Neonicotinoid insecticides in surface water from the central Yangtze River, China. Chemosphere. 2019:229:452-60

Mashao G, Ramohlola KE, Mdluli SB, Monama GR, Hato MJ, Makgopa K, Molapo KM, Ramoroka ME, Iwuoha El, Modibane KD. Zinc-based zeolitic benzimidazolate framework/polyaniline nanocomposite for electrochemical sensing of hydrogen gas. Mater Chem Phys. 2019:230:287-98.

Mashile PP, Mpupa A, Nomngongo PN. Adsorptive removal of microcystinLR from surface and wastewater using tyre-based powdered activated carbon: kinetics and isotherms. Toxicon. 2018a;145:25-31.

Mashile GP, Mpupa A, Dimpe MK, Nomngongo PN. Magnetic activated carbon@ iron oxide@manganese oxide composite as an adsorbent for preconcentration of microcystin - LR in surface water, tap water, water and wastewater. Environ Nanotechnol Monit Manag. 2018b; 10:199-205.

Mehdinia A, Aziz-Zanjani MO. Advances for sensitive, rapid and selective extraction in different configurations of solid-phase microextraction. TrAC Trends Anal Chem. 2013;51:13-22.

Mogolodi Dimpe K, Nomngongo PN. Application of activated carbondecorated polyacrylonitrile nanofibers as an adsorbent in dispersive solid-phase extraction of fluoroquinolones from wastewater. J Pharm Anal. 2019;9:117-26.

Mpupa A, Mashile GP, Nomngongo PN. Ultrasound-assisted dispersive solid phase nanoextraction of selected personal care products in wastewater followed by their determination using high performance liquid chromatography-diode array detector. J Hazard Mater. 2019;370:33-41.

Mui EL, Cheung W, Valix M, McKay G. Mesoporous activated carbon from waste tyre rubber for dye removal from effluents. Microporous Mesoporous Mater. 2010;130:287-94

Munonde TS. Preparation of modified magnetic nanocomposites and their application for preconcentration and speciation of selected trace elements in river water samples. Johannesburg: University of Johannesburg; 2017

Naushad M, Alqadami AA, Al-Kahtani AA, Ahamad T, Awual MR, TatarchukT. Adsorption of textile dye using para-aminobenzoic acid modified activated carbon: kinetic and equilibrium studies. J Mol Liq. 2019;296:112075.
Njoku V, Foo K, Asif M, Hameed B. Preparation of activated carbons from rambutan (Nephelium lappaceum) peel by microwave-induced $\mathrm{KOH}$ activation for acid yellow 17 dye adsorption. Chem Eng J. 2014;250:198-204.

Peyton GR. The free-radical chemistry of persulfate-based total organic carbon analyzers. Mar Chem. 1993;41:91-103.

Pietrzak D, Kania J, Kmiecik E, Malina G, Wątor K. Fate of selected neonicotinoid insecticides in soil-water systems: current state of the art and knowledge gaps. Chemosphere. 2020;255:126981.

Ramohlola KE, Masikini M, Mdluli SB, Monama GR, Hato MJ, Molapo KM, Iwuoha El, Modibane KD. Electrocatalytic hydrogen production properties of poly (3-aminobenzoic acid) doped with metal organic frameworks. Int J Electrochem Sci. 2017a;12:4392-405.

Ramohlola KE, Masikini M, Mdluli SB, Monama GR, Hato MJ, Molapo KM, Iwuoha El, Modibane KD. Electrocatalytic hydrogen evolution reaction of metal organic frameworks decorated with poly (3-aminobenzoic acid). Electrochim Acta. 2017b;246:1174-82.

Rodríguez R, Avivar J, Leal LO, Cerdà V, Ferrer L. Strategies for automating solidphase extraction and liquid-liquid extraction in radiochemical analysis. TrAC Trends Anal Chem. 2016;76:145-52.

Sadeghi MM, Rad AS, Ardjmand M, Mirabi A. Preparation of magnetic nanocomposite based on polyaniline/ $/ \mathrm{Fe}_{3} \mathrm{O}_{4}$ towards removal of lead (II) ions from real samples. Synth Met. 2018;245:1-9.

Sánchez-Bayo F, Hyne RV. Detection and analysis of neonicotinoids in river waters-development of a passive sampler for three commonly used insecticides. Chemosphere. 2014;99:143-51.

Shabanian M, Khoobi M, Hemati F, Khonakdar HA, Wagenknecht U, Shafiee A. New PLA/PEl-functionalized $\mathrm{Fe}_{3} \mathrm{O}_{4}$ nanocomposite: preparation and characterization. J Ind Eng Chem. 2015;24:211-8.

Song X, Xie J, Zhang M, Zhang Y, Li J, Huang Q, He L. Simultaneous determination of eight cyclopolypeptide antibiotics in feed by high performance liquid chromatography coupled with evaporation light scattering detection. J Chromatogr B. 2018;1076:103-9.

Spietelun A, Marcinkowski Ł, de la Guardia M, Namieśnik J. Recent developments and future trends in solid phase microextraction techniques towards green analytical chemistry. J Chromatogr A. 2013;1321:1-13.

Tarhan T, Ulu A, Sariçam M, Çulha M, Ates B. Maltose functionalized magnetic core/shell Fe304@Au nanoparticles for an efficient l-asparaginase immobilization. Int J Biol Macromol. 2020;142:443-51.

Treder N, Maliszewska O, Olędzka I, Kowalski P, Miękus N, Bączek T, Bień E, Krawczyk MA, Adamkiewicz-Drożynska E, Plenis A. Development and validation of a high-performance liquid chromatographic method with a fluorescence detector for the analysis of epirubicin in human urine and plasma, and its application in drug monitoring. J Chromatogr B. 2020;1136:121910.

Valasques GS, dos Santos AMP, de Souza VS, Teixeira LSG, Alves JPS, Souza MJ, dos Santos WPC, Bezerra MA. Multivariate optimization for the determination of cadmium and lead in crude palm oil by graphite furnace absorption atomic spectrometry after extraction induced by emulsion breaking. Microchem J. 2019:153:104.

Vichapong J, Burakham R, Srijaranai S. Vortex-assisted surfactant-enhancedemulsification liquid-liquid microextraction with solidification of floating organic droplet combined with HPLC for the determination of neonicotinoid pesticides. Talanta. 2013;117:221-8.

Vichapong J, Burakham R, Srijaranai S. In-coupled syringe assisted octanolwater partition microextraction coupled with high-performance liquid chromatography for simultaneous determination of neonicotinoid insecticide residues in honey. Talanta. 2015;139:21-6.

Vu HC, Dwivedi AD, Le TT, Seo S-H, Kim E-J, Chang Y-S. Magnetite graphene oxide encapsulated in alginate beads for enhanced adsorption of $\mathrm{Cr}(\mathrm{VI})$ and $\mathrm{As}(\mathrm{V})$ from aqueous solutions: role of crosslinking metal cations in pH control. Chem Eng J. 2017;307:220-9.

Wang W, Li Y, Wu Q, Wang C, Zang X, Wang Z. Extraction of neonicotinoid insecticides from environmental water samples with magnetic graphene nanoparticles as adsorbent followed by determination with HPLC. Anal Methods. 2012;4:766-72.

Wang D, Chen Z, Zhou Z, Wang D, Yu J, Gao S. Catalytic upgrading of volatiles from coal pyrolysis over sulfated carbon-based catalysts derived from waste red oil. Fuel Process Technol. 2019:189:98-109.

Yamamoto I, Casida JE. Nicotinoid insecticides and the nicotinic acetylcholine receptor. Tokyo: Springer; 1999. 
Yáñez KP, Martín MT, Bernal JL, Nozal MJ, Bernal J. Trace analysis of seven neonicotinoid insecticides in bee pollen by solid-liquid extraction and liquid chromatography coupled to electrospray ionization mass spectrometry. Food Anal Methods. 2014;7:490-9.

Yi X, Zhang C, Liu H, Wu R, Tian D, Ruan J, Zhang T, Huang M, Ying G. Occurrence and distribution of neonicotinoid insecticides in surface water and sediment of the Guangzhou section of the Pearl River, South China. Environ Pollut. 2019;251:892-900.

Zare EN, Lakouraj MM, Ashna A. Synthesis of conductive poly (3-aminobenzoic acid) nanostructures with different shapes in acidic ionic liquids medium. J Mol Liq. 2018;271:514-21.

Zhang B-T, Zheng X, Li H-F, Lin J-M. Application of carbon-based nanomaterials in sample preparation: a review. Anal Chim Acta. 2013;784:1-17.

Zhang J, Li R, Ding G, Wang Y, Wang C. Sorptive removal of phenanthrene from water by magnetic carbon nanomaterials. J Mol Liq. 2019;293:111540.

Zhao Y, Gong X, Si X, Wei Z, Yang C, Zhang S, Zhang X. Coupling a solid phase microextraction (SPME) probe with ambient MS for rapid enrichment and detection of phosphopeptides in biological samples. Analyst. 2015;140:2599-602.

Zhao G, Zou J, Chen X, Liu L, Wang Y, Zhou S, Long X, Yu J, Jiao F. Iron-based catalysts for persulfate-based advanced oxidation process: microstructure, property and tailoring. Chem Eng J. 2020;421:127845.

Zhou Q, Ding Y, Xiao J. Sensitive determination of thiamethoxam, imidacloprid and acetamiprid in environmental water samples with solid-phase extraction packed with multiwalled carbon nanotubes prior to high-performance liquid chromatography. Anal Bioanal Chem. 2006;385:1520-5.

Zou Y, Li W, Yang L, Xiao F, An G, Wang Y, Wang D. Activation of peroxymonosulfate by sp2-hybridized microalgae-derived carbon for ciprofloxacin degradation: importance of pyrolysis temperature. Chem Eng J. 2019;370:1286-97.

\section{Publisher's Note}

Springer Nature remains neutral with regard to jurisdictional claims in pub-

lished maps and institutional affiliations.

\section{Submit your manuscript to a SpringerOpen ${ }^{\circ}$ journal and benefit from:}

- Convenient online submission

- Rigorous peer review

- Open access: articles freely available online

- High visibility within the field

- Retaining the copyright to your article

Submit your next manuscript at $\boldsymbol{\nabla}$ springeropen.com 